\title{
Pra cima com a viga, moçada
}

Rise high the roof beam, carpenters

Rui M. B. Maciel

$\mathrm{O}$ título em português desta deliciosa história de J. D. Salinger tem me inspirado muitas vezes, quando me deparo com aquela sensação de bem-estar, subsequente a uma tarefa bem concluída (1). Esse fato acontece, especialmente, quando se recebe uma mensagem de aceitação para a publicação de um "paper" que foi bem desenhado, bem executado e bem escrito. Essa sensação de bem-estar é muito boa, mas pode trazer a percepção de que estamos indo bem no difícil caminho da ciência, o que pode nos levar ao imobilismo, que, por sua vez, nos coloca imediatamente para trás na competição constante na carreira de médico/cientista dedicado à pesquisa e ao ensino. Assim, depois do aceite do editor, festejo com todo o grupo - com uma taça de bom champanhe, mas logo a seguir lanço o mote acima, para que reiniciemos o trabalho imediatamente, uma vez que é importante progredir, melhorar sempre, mudar de patamar e não ficar fazendo sempre o mesmo.

Esta introdução é para se fazer uma reflexão quanto ao que queremos dos ABE\&M? A chamada "Pra cima com a viga, moçada" é para o novo editor que assumirá no próximo ano, mas é também um repto aos endocrinologistas brasileiros no sentido de fortalecer, enobrecer e dar sustentabilidade aos ABE\&M. O progresso dos ABE\&M como revista científica tem sido evidente. De uma publicação irregular do ponto de vista de conteúdo e periodicidade - que acompanhei como jovem endocrinologista e editor-chefe, os ABE\&M evoluíram, nestes últimos 10 anos, para uma revista científica de bom conteúdo, periodicidade e certificações internacionais - especialmente as indexações nas bases de dados do Index Medicus e do ISI Web of Knowledge/Journal Citation Report - JCR $(2,3)$. Essa melhoria deveu-se à dedicação de seus editoreschefes neste período, Claudio Kater e Edna Kimura, de seus coeditores, do apoio das diversas diretorias da SBEM e, principalmente, da melhoria da infraestrutura de pesquisa e da qualificação dos diversos Programas de Pós-Graduação e de Residência na Endocrinologia Brasileira, decorrentes do apoio substancial do CNPq, Capes, FINEP e Fapesp, circunstâncias que geraram a formação de recursos humanos de qualidade e grupos sustentáveis de pesquisa, que propiciaram a produção de trabalhos de valor, reconhecidos pela comunidade científica internacional (4).

Muito bem, em decorrência desses progressos, buscamos com afinco e competência o objetivo da indexação dos ABE\&M e fomos merecidamente agraciados (2). Porém, se essa iniciativa nos colocou no desejado jogo da competição científica internacional, ao mesmo tempo nos fez olhar com realismo para a situação: ainda estamos longe de adquirir o status de revista internacional de referência e de escolha para a maioria dos autores, incluindo aqui os brasileiros. Para uma sociedade científica que se arvora em ser a terceira do mundo em número de associados e ter sido sede do Congresso Internacional de Endocrinologia, não é honroso, nem digno de elogios, possuir a revista que ocupa o $95^{\circ}$. lugar em citações entre os 105 títulos indexados publicados na área de endocrinologia, diabetes e metabolismo na avaliação atual do JCR $(5,6)$. Outras sociedades menores que a nossa têm revistas mais bem classificadas; porém, outras sociedades mais tradicionais, como a francesa, que tem descurado da renovação e do multiculturalismo, estão numa posição inferior à nossa (6).
Professor titular, Disciplina de Endocrinologia, Departamento de Medicina, Escola Paulista de Medicina, Universidade Federal de São Paulo (Unifesp/ EPM), São Paulo, SP, Brasil
Correspondência para: Rui M. B. Maciel

Laboratório de Endocrinologia Molecular, Disciplina de Endocrinologia, Unifesp/EPM Rua Pedro de Toledo, 669, $11^{\circ}$. andar 04039-032 - São Paulo, SP, Brasil rui.maciel@unifesp.br 
Os editores têm feito a sua parte e se esforçado para a melhoria do índice de citações, considerando-se os diversos progressos implantados na gestão da revista no correr dos anos; assim, a possibilidade da submissão eletrônica, a disponibilidade dos artigos permanentemente on line sem custo para os leitores - o que dá enorme vantagem competitiva em relação a revistas pagas, a celeridade em alguns processos de revisão, a ajuda na melhoria dos textos por meio da contribuição editorial dos coeditores e revisores, as edições especiais e a recente procura da revista por cientistas internacionais, ainda que primariamente da América Latina, são evidências palpáveis desse esforço de colocar os ABE\&M numa posição de maior destaque. Assim, depois da implementação da submissão on line houve um aumento de cerca de $90 \%$ no número de submissões nos anos de 2008 e 2009, quando comparado a 2007 (7). Depois da disponibilidade dos artigos on line, o número de visitas aos ABE\&M elevou-se brutalmente, não apenas em acessos provenientes de pessoas na língua portuguesa, mas também em inglês: neste último ano tivemos 2 milhões de acessos em português e 450 mil em inglês, o que indica que os estrangeiros estão buscando nossos artigos (8).

Entretanto, além das melhorias continuadas, é fundamental que tenhamos agora uma mudança radical. É como se precisássemos nos ABE\&M de algo equivalente a uma mudança de marcha quando dirigimos um automóvel; já passamos da primeira para a segunda marcha por ocasião da indexação, mas agora, ao adentrar na autoestrada da competitividade científica, não dá para ficar na segunda marcha, o que nos impedirá de obter a velocidade de cruzeiro e de sustentabilidade necessárias, mas evoluir para a terceira, para a quarta, para a quinta marcha. $\mathrm{Na}$ autoestrada da competição internacional, é necessário transformar os ABE\&M e deixá-los mais competitivos, de modo equivalente ao que tem acontecido com as publicações de autores brasileiros em revistas de circulação internacional: assim, a citação média de autores brasileiros entre 1998 e 2008 aumentou muito e chega à média de $6 /$ investigador, 0 que nos coloca ainda atrás dos desenvolvidos, mas muito mais próximos deles, como nunca estivemos (americanos, 14; ingleses, 12; alemães, 11; franceses e italianos, 10) (9). Além do aumento do número de citações, mas diretamente decorrente dele, tem incrementado a participação de brasileiros como palestrantes em eventos internacionais de envergadura, como, por exemplo, as reuniões recentes da Endocrine Society e do International Thyroid Congress.
Se os editores têm feito sua parte de modo diligente para a melhoria da classificação dos ABE\&M no concerto das publicações de endocrinologia, o que falta agora, como lançado acima, é um repto, um incitamento, um desafio, uma provocação, uma instigação à classe endocrinológica brasileira no sentido de: a) enviar mais os seus "papers" aos ABE\&M, que são lidos, visitados e apresentam índice de citações aproximado a revistas estrangeiras utilizadas por autores brasileiros, como Journal of Endocrinological Investigation, Journal of Pediatric Endocrinology and Metabolism, The Endocrinologist, entre outras; b) citar seus trabalhos e os de seus colegas publicados nos ABE\&M (estratagema empregado por autores europeus para melhorar a classificação do European Journal of Endocrinology e pelos cardiologistas brasileiros nos Arquivos Brasileiros de Cardiologia). Infelizmente, em nossa especialidade, não é incomum ver trabalhos brasileiros em que se citam, na discussão, dados de lugares remotos e ignoram-se trabalhos nacionais publicados nos ABE\&M; c) responder prontamente quando convidado a ser revisor de artigo, seja no sentido positivo da rápida elaboração do parecer, seja no negativo, indicando sua impossibilidade de contribuir desta vez, mas fornecendo alternativas, para que os editores garantam a celeridade da resposta ao autor.

Há alguns anos, Claudio Kater escreveu "Fôssemos mais valorizados aqui mesmo entre nossos pares, deixando de lado a ambição, a docilidade ou a subserviência científica às revistas estrangeiras, nem sempre superiores e de mérito científico até discutível, e talvez estivéssemos sendo aquinhoados com um maior número de contribuições de melhor qualidade" (7); isso, porém, foi escrito em 2002, hoje a realidade é outra, a ciência brasileira progrediu, o número e a qualidade de publicações aumentaram, o número de centros produtores de conhecimento se multiplicou (10) e nossos cientistas/endocrinologistas deveriam se empenhar mais para a melhoria dos ABE\&M.

Considero também que a classificação pífia dos ABE\&M e dos Annales d' Endocrinologie é decorrente da barreira da língua; uma vez que os $A B E \& M$ já publicam também artigos em inglês, minha sugestão é que se modifique a informação referente à língua nas bases de dados de citações, adicionando-se o inglês ao português, além de se exigir que os "abstracts" tenham uma versão inteligível e correta. Adicionalmente, havendo a possibilidade, por parte da revista, em facilitar aos autores a publicação do artigo completo também vertido para o inglês, por tradutor competente, contri- 
buiria muito para a visibilidade e aumento de citações. A publicação dos artigos dos ABE\&M em inglês, além do português, faria com que os leitores internacionais se interessassem em ler artigos ou sumários neles publicados quando localizassem pesquisas de interesse no PubMed. A Acta Endocrinologica Scandinavica, que se transformou no European Journal of Endocrinology, publica seus artigos em inglês desde o final dos anos 1940, pois os escandinavos perceberam que a língua científica mudou do francês e do alemão para o inglês depois da $2^{\mathrm{a}}$. Guerra Mundial; comunicar-se cientificamente em inglês foi um fator de progresso para a ciência escandinava.

Se mudanças radicais como essas não forem feitas, as citações dos artigos citados nos ABE\&M não acontecerão e ficaremos apenas pensando no desejo que tivemos de construir uma sociedade científica que tenha um projeto de futuro brilhante. Vamos construí-lo agora, pois "a memória só importa realmente - para os indivíduos, para a coletividade, para a civilização - se ligar a impressão do passado com o projeto do futuro, se nos possibilitar agir sem esquecer o que queríamos fazer, tornar-se sem deixar de ser, e ser sem deixar de tornar-se" (11). Nas 11 referências, entre Salinger e Calvino, incluo qua- tro referências dos ABE\&M e duas da Nature! Nada mal para ser coerente com o meu discurso.

\section{REFERÊNCIAS}

1. Salinger JD. Pra cima com a viga, moçada! Tradução de Alberto Martins "Rise high the roof beam, carpenters". São Paulo: Brasiliense; 1984.

2. Guimarães V. História da indexação dos $A B E \& M$ : razão, trabalho e emoção. Arq Bras Endocrinol Metab. 2004;48(2):217-9.

3. Kater CE. Reflexos imediatos da indexação internacional e atualização da política editorial dos ABE\&M. Arq Bras Endocrinol Metab. 2004;48(4):440-2.

4. Brazil's biotech boom. Nature. 2010;466(7304):295.

5. Kimura ET. Fator de impacto. Arq Bras Endocrinol Metab. 2008;52(6):925-6.

6. 2009 Journal Citation Report, Endocrinology \& Metabolism. Disponível em: www.JCR-web. Acesso em: 13 Ago 2010.

7. Kater CE. A respeito das citações dos "Arquivos". Arq Bras Endocrinol Metab. 2002;46(5):491-2.

8. Arquivos Brasileiros de Endocrinologia e Metabologia. Estatísticas. Acesso aos artigos por idioma. Disponível em: http://www. scielo.br (acesso em Aug 12, 2010).

9. Essential Science Indicators from Thomson Reuters. Top 20 Countries in all fields, 1998-August 31, 2008. Disponível em: http://sciencewatch.com/dr/cou/2008 (acesso em Aug 12, 2010).

10. Ready for the best, editorial. Nat Mater. 2010;9(7):527.

11. Calvino I. Por que ler os clássicos. Tradução de Nilson Moulin "Perche leggere I classici". São Paulo: Companhia das Letras; 1993. p. 18. 